\title{
2002s-62
}

\section{Circuit Breakers and the Tail Index of Equity Returns}

John W. Galbraith and Serguei Zernov

\section{Série Scientifique}

Scientific Series

\author{
Montréal \\ Juin 2002
}

(C) 2002 John Galbraith and Serguei Zernov. Tous droits réservés. All rights reserved. Reproduction partielle permise avec citation du document source, incluant la notice $($ ).

Short sections may be quoted without explicit permission, if full credit, including $\odot$ notice, is given to the source

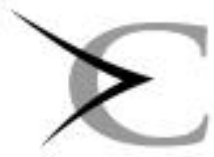

\section{CIRANO \\ Centre interuniversitaire de recherche en analyse des organisations}




\section{CIRANO}

Le CIRANO est un organisme sans but lucratif constitué en vertu de la Loi des compagnies du Québec. Le financement de son infrastructure et de ses activités de recherche provient des cotisations de ses organisationsmembres, d'une subvention d'infrastructure du ministère de la Recherche, de la Science et de la Technologie, de même que des subventions et mandats obtenus par ses équipes de recherche.

CIRANO is a private non-profit organization incorporated under the Québec Companies Act. Its infrastructure and research activities are funded through fees paid by member organizations, an infrastructure grant from the Ministère de la Recherche, de la Science et de la Technologie, and grants and research mandates obtained by its research teams.

\section{Les organisations -partenaires / The Partner Organizations}

-École des Hautes Études Commerciales

-École Polytechnique de Montréal

-Université Concordia

-Université de Montréal

-Université du Québec à Montréal

-Université Laval

-Université McGill

-Ministère des Finances du Québec

-MRST

-Alcan inc.

-AXA Canada

-Banque du Canada

- Banque Laurentienne du Canada

- Banque Nationale du Canada

-Banque Royale du Canada

- Bell Canada

- Bombardier

-Bourse de Montréal

-Développement des ressources humaines Canada (DRHC)

-Fédération des caisses Desjardins du Québec

•Hydro-Québec

-Industrie Canada

-Pratt \& Whitney Canada Inc.

- Raymond Chabot Grant Thornton

-Ville de Montréal 


\title{
Circuit Breakers And the Tail Index of Equity Returns*
}

\author{
John W. Galbraith ${ }^{\dagger}$ and Serguei Zernov ${ }^{\dagger}$
}

\section{Résumé / Abstract}

Utilisant l'indice de queue de distribution (index tail) des rendements financiers sur actions dans les marchés américains comme mesure sommaire des comportements extrêmes, nous examinons les changements dans le marché des actions entourant le développement de programmes automatiques de transaction (Trading Program) pour l'assurance de portefeuille, le krach de 1987, l'introduction des coupe-circuits et autres changements dans les systèmes financiers. De nouveaux tests, récemment développés, permettent l'inférence statistique sur le changement des comportements extrêmes sur une longue période; tests qui sont valides dans le cas d'hétéroscédasticité conditionnelle. L'hypothèse nulle est que l'indice de queue de distribution est constant alors que l'hypothèse alternative est le changement de cet indice à une date inconnue. Nous avons trouvé de manière très significative que d'une part, l'indice de queue de distribution a diminué (la probabilité d'évènements extrêmes a augmenté) au début de la période des programmes de transactions. D'autre part, l'introduction de coupe-circuits a augmenté cet indice mais est resté plus faible que sa valeur avant lintroduction des programmes de transactions. Les estimateurs de l'indice de queue de distribution suggèrent qu'il n'a pas retrouvé sa valeur initiale.

Using the tail index of returns on US equities as a summary measure of extreme behaviour, we examine changes in the equity markets surrounding the development of program trading for portfolio insurance, the crash of 1987, and the subsequent introduction of circuit breakers and other changes in market architecture. Recently-developed tests for the null of constancy of the tail index, versus the alternative of a change at an unknown date, permit inference on changes in extreme behaviour over a long time period while allowing for second-moment dependence in the return data. We find strong evidence of a decrease in the tail index (increase in the probability of extreme events) around the beginning of large scale program trading, and weaker, but still substantial, evidence of further significant change in the tail index following the introduction of circuit breakers. Point estimates of the tail index suggest that the tail index has nonetheless not regained pre-program-trading levels.

Codes JEL : G10, G18

Mots clés : Coupe-circuits, tests sur le changement structurel, indice de queue de distribution.

Keywords : Circuit breaker, structural change tests, tail index

\footnotetext{
* We thank the Centre Interuniversitaire de recherche en analyse des organisations (CIRANO), the Fonds québécois de la recherche sur la société et la culture and the Social Sciences and Humanities Research Council of Canada (SSHRC) for financial support of this research.

$\dagger$ McGill University and CIRANO

$\ddagger$ McGill University
} 


\section{INTRODUCTION}

After the equity market crash of October 1987, a number of changes were made to markets' operating procedures in order to limit the program trading which was widely blamed for the crash. In particular, 'circuit breakers' were introduced whereby, following drops of specified size, trading is temporarily halted or restricted. One interpretation of the intent behind these restrictions is that they were designed to return the equity markets' behaviour in extreme circumstances to roughly the state prevailing before the introduction of program trading. That is, equity markets have always exhibited occasional extreme events, but program trading was perceived to have altered the extreme behaviour of markets from the state prevailing when investors' judgments alone governed trades. Circuit breakers and other regulatory changes might be viewed as an attempt to return to this pre-existing state. ${ }^{1}$

In this paper we investigate the empirical facts lying behind this interpretation of events, using formal statistical tests to detect changes in the behaviour of extremes of equity market returns. In particular, we address these two questions: (i) did the period following the introduction of program trading show a genuine change in the character of extreme return events? If so, (ii) did the introduction of market reforms lead to a further discernible break in tail behaviour, returning the markets to a state similar to that prevailing before the introduction of program trading?

To address these questions we use the tail index of the density of equity returns, on both the Dow Jones Industrial and the S\&P 500 indices. With the tail index as our measure of extreme behaviour in returns, our questions can be formulated somewhat more precisely as follows: did the period of program trading represent a structural break in the tail index of equity market returns? If so, did market reforms lead to a further significant break, returning the tail index approximately to its pre-existing value?

There have been several previous empirical studies of the effects of circuit breakers, including those of Ma, Rao and Sears (1989a,b), Santoni and Liu (1993), and Booth and Broussard (1998), using data from US bond and commodity markets and the NYSE respectively. The Ma et al. and Santoni and Liu studies examine the impact of circuit breakers on market volatility, using in the former cases measures of volatility based on daily closing prices or cumulative average returns in one-minute interval data, and in the latter ARCH models of the daily conditional volatility. These results are mixed, with the Ma et al. studies of bond and commodity markets suggesting lower volatility after the introduction of trading restrictions, whereas Santoni and Liu find little evidence for a reduction in conditional volatility in S\&P 500 index data. Booth and Broussard, in common with the present paper, study

${ }^{1}$ An alternative interpretation, of course, is that the changes were introduced with the aim of enforcing some optimal degree of extreme behaviour. 
tail properties of NYSE index data, and present detailed evidence on the evolving size of the circuit breaker triggers as a proportion of the index value. We will refer further to these results below.

Studies on equity markets outside the U.S. include those of Roll (1989), Bertero and Mayer (1990) and Lauterbach and Ben-Zion (1993). Lauterbach and Ben-Zion examine the period of the 1987 crash on the Tel Aviv market, for which circuit breaker mechanisms were in place in 1987, and for which order imbalance data are also available. These authors suggest that trading restrictions did not affect the overall degree of decline, but did smooth returns around the crash date. Roll (1989) and Bertero and Mayer (1990) each compare 23 stock markets around the time of the crash, in monthly and daily data respectively; the latter study finds a substantial impact of circuit breakers on price declines, while the former does not. Nonetheless, as Lauterbach and Ben-Zion point out, trading restrictions differ substantially across international markets, making the results of such exercises difficult to interpret.

The present study is able to provide substantial further evidence on the effects of circuit breakers, for several reasons. First, by concentrating on overall characterization of the tail of the return distribution rather than on volatility measures, our results are focused on extreme events; we are able to examine the evolution of this measure of extreme behaviour over time. Recent work on tests for a structural break in the tail index at an unknown date (Quintos et al. 2001) and on tail index estimation with dependent sequences (Hsing 1991) allows us to test for such changes in data such as equity returns which display (second moment) dependence. The Quintos et al. tests, because they do not require a priori specification of a break point, permit examination of the period of gradual emergence of program trading as an important feature of US equity markets, as well as the period after which circuit breakers were introduced. These tests use Hsing's results to allow for the dependence present in such data.

A second element in our additional evidence is the time series of post-circuitbreaker daily returns in US stock markets. Because tail index estimation is usually based only on data from the tails of the empirical density, very large samples are typically required in order to obtain reliable estimates. Nonetheless, with over a dozen years of post-reform data, it is now possible to obtain reasonable tail index estimates for this period. With a time series of daily index returns extending back to 1928 (Dow Jones Industrial Average), and 1950 (S\&P 500), we are able to estimate and test for changes in the tail index both in long samples and in shorter samples dating from the introduction of large-scale program trading.

The next section of the paper describes the regulatory changes in US equity markets over the period of interest, and the data used in testing. Section 3 explains the statistical methods used for tail index estimation and testing for changes in this index; Section 4 presents the results of the estimation and inferential procedures, 
and interprets the evidence.

\section{Data And MARKet STRUCTURe}

This study examines the two longest-standing indices of U.S. equity prices, the Dow Jones Industrial Average and the broader S\&P 500 Index. Because the structure of circuit breakers is based on daily stock price changes-that is, the measure of price change which these devices use is implicitly set to zero at the beginning of each trading day-we examine daily changes in these index levels. Daily information is available for a long historical period for the Dow Jones index; we use data from October 1 1928, the date at which the index took its current 30-stock form. Our daily sample of the S\&P 500 begins on January 3 1950; both series end in March of 2002, for total sample sizes of 18443 days (DJIA) and 13129 days (S\&P). Each of these data series is transformed to daily logarithmic returns, $r_{t}=\ln \left(\frac{p_{t}}{p_{t-1}}\right)$, where $p_{t}$ is the index value at time $t$, reducing sample sizes by 1 .

Post-1987 changes in the structure and regulation of these markets have been thoroughly described in the literature; see in particular Lindsey and Pecora (1998). We will confine ourselves here to a brief review of some elements that are especially important for our present purposes.

The first 'circuit breakers', introduced in October 1998, required a trading halt of one hour following a fall in the DJIA of 250 points from the previous day's close, and of two additional hours if in subsequent trading the total decline reached 400 points. In July of 1996, the durations of these required trading halts were reduced to 30 minutes and one hour respectively, and in January 1997 the trigger points were changed (reflecting in part the increase in value of the DJIA which had made the previous triggers smaller percentages of the index value), to 350 and 550 points. Additional restrictions govern entering of index arbitrage trades when the DJIA either advances or declines 50 points from the previous close, and govern market orders involving program trading when the S\&P 500 futures contract falls 12 points below the previous day's close (Lindsey and Pecora 1998).

Booth and Broussard (1998) document the decline in the initial 250-point trigger as a percentage of the DJIA from approximately 12 percent at its introduction to less than half of this percentage near the end of 1995. It is clear, then, that the degree to which these triggers have constrained trading changed substantially over time; Booth and Brousard estimate the probabilities of declines exceeding the trigger values, and note substantial corresponding changes over time in these estimated probabilities.

The period in which program trading, particularly for purposes of portfolio insurance, became important in U.S. equity markets cannot be dated as precisely as can regulatory changes. ${ }^{2}$ Nonetheless, this period is of interest insofar as we are

${ }^{2}$ Program trading for portfolio insurance, as opposed to arbitrage, is particularly 
interested in the question of whether circuit breakers and other regulatory changes can be viewed as having returned the markets to some state prevailing before the era of program trading. An indication of the point at which program trading for portfolio insurance became an important element in markets will govern our selection below of a sub-sample for post-program-trading tests; based on the value of securities protected by such portfolio insurance, we have chosen 2 January 1985 as the beginning of this sample from the period of significant program trading.

In the next section, we turn to the tail index with which we will characterize the extremes of the return distribution through these historical periods, and describe the methods by which we will estimate the value of the tail index and test for changes over time.

\section{Statistical METHODS}

The tail index characterizes the rate at which probability mass falls away in the tail of a distribution; a relatively high tail index corresponds with relatively low probability of extreme events. Let $\left\{X_{i}\right\}$ be a sequence of random variables with common distribution function $F(x)$, so that $1-F(x)$ is the probability of observing a value exceeding $x$. Then (see, for example, Hsing 1991) $1-F(x)$ is said to be regularly varying at $\infty$ if there exists $\alpha>0$ such that

$$
(1-F(h x)) /(1-F(x)) \rightarrow h^{-\alpha} \text { as } x \rightarrow \infty, \forall h>0 .
$$

We refer to $\alpha$ as the tail index parameter, and note that (1) implies

$$
(1-F(x)) \rightarrow k x^{-\alpha} \text { as } x \rightarrow \infty \text {, for some } k>0 .
$$

While a number of estimators of $\alpha$ are available, we will use that of Hill (1975), for several reasons: the estimation procedure does not depend on existence of the fourth moment of the data; the estimator has been found to perform relatively well on sample sizes available in financial data (Kearns and Pagan 1997); and, particularly importantly for our present purpose, it is the basis of the structural break tests of Quintos et al. (2001). Other methods have been proposed to reduce bias in such estimates, in particular the ML method of Feuerverger and Hall (1999), which treats the tails as approximated by a mixture of Pareto densities such that (adapting to the present case of a tail at infinity rather than at the origin), $1-F(x)=$

$k_{1} x^{-\alpha}\left(1+k_{2} x^{-\beta}+o\left(x^{-\beta}\right)\right)$ is explicitly used as a model, leading to estimates of both $\alpha$ and $\beta$. Note that this model is compatible with (3.1) as $x \rightarrow \infty$. However,

important here because of the potential for large scale sales of securities triggered by an initial market decline. 
our interest here is not in the absolute level of the tail index, but in possible changes over time; the methods of inference concerning structural change are therefore our primary concern.

Hill's estimator is based on the $m$ largest order statistics of the sample. Following the notation of Quintos et al., define the order statistics from the original sample $\left\{X_{1}, X_{2}, \ldots X_{T}\right\}$ as $\left\{X_{(1)}^{T}, X_{(2)}^{T}, \ldots X_{(T)}^{T}\right\}, X_{(1)}^{T} \leq X_{(2)}^{T} \leq \ldots \leq X_{(T)}^{T}$. Choose the largest $m_{T}$ of these, $X_{\left(T-m_{t}+1\right)}^{T}$ to $X_{(T)}^{T}$, for estimation on the right tail of the distribution (for the left tail, multiply the smallest $m_{T}$ values by -1 ). The Hill estimator of $\alpha$ is then

$$
\hat{\alpha}_{T}=\left[m_{T}^{-1} \sum_{i=1}^{m_{T}} \ln X_{(T-i+1)}^{T}-\ln X_{\left(T-m_{T}+1\right)}^{T}\right]^{-1} .
$$

Estimation of the tail index parameter generally requires a relatively large sample, because only a small proportion of the sample occurs, by definition, in the tails; it is common in estimation to use a proportion such as $10 \%$ of the sample size, following DuMouchel (1983) who suggest $m_{T}$ be a fixed proportion not exceeding $0.1 T$. All sequences of tail index estimates in the present paper are based on the Hill estimator, and vary only in the definition of the sample used for estimation. In recursive estimation, a sequence of estimators is presented in which the sample size is augmented at each date by the latest data point; in rolling estimation, a fixed sample size is maintained by dropping the earliest data point each time a new data point is added. Our estimates are updated daily and are presented graphically below.

The structural change tests of Quintos et al. (2001) are based on these sequences of tail index estimates. The null hypothesis is that the tail index has the constant value $\alpha$ over the real interval $t \in\left[t_{0}, T-t_{0}\right]$, with alternative of departure from $\alpha$ at some point in the interval, and is tested with sequences of estimates defined over different sets of samples. Recursive estimates produce a sequence of estimates $\hat{\alpha}_{t}$ using samples $1, \ldots t$, for $t=t_{0}, t_{0}+1, \ldots T-t_{0}$; rolling estimates use samples $1+\left(t-t_{0}\right), \ldots t$, with $t$ indexed over the same values, for a constant sample size $t_{0}$. The sequential tests use both a recursive set of estimates and a reverse recursive set, ${ }^{3}$ labelled $\hat{\alpha}_{t}^{(-)}$, defined over samples $1, \ldots t$ and $t+1, \ldots T$ respectively, where once again $t$ indexes the values $t_{0}, t_{0}+1, \ldots T-t_{0}$. The sequences of test

\footnotetext{
${ }^{3}$ Recall that the reverse recursive estimator begins with an estimate on the maximum sample, here $t_{0}+1, \ldots T$, and drops a point from the beginning of the sample to produce each new estimate in the sequence.
} 
statistics are (in a slightly modified notation):

$$
\begin{aligned}
& Z_{1}(t)=\left(\frac{t m_{t}}{T}\right)\left(\frac{\hat{\alpha}_{t}}{\hat{\alpha}_{T}}-1\right)^{2} \\
& Z_{2}(t)=\left(\frac{t_{0} m_{0}}{T}\right)\left(\frac{\hat{\alpha}_{\left(t_{0}, t\right)}}{\hat{\alpha}_{T}}-1\right)^{2} \\
& Z_{3}(t)=\left(\frac{t m_{t}}{T}\right)\left(\frac{\hat{\alpha}_{t}}{\hat{\alpha}_{t}^{(-)}}-1\right)^{2}
\end{aligned}
$$

where $\hat{\alpha}_{\left(t_{0}, t\right)}$ is the tail index estimate on the rolling sample of size $t_{0}$ and $m_{0}$ is the corresponding number of order statistics.

The test statistics are $\sup _{t} Z_{i}(t), i=1,2,3$, and in the IID case have asymptotic distributions obtained and tabulated by Quintos et al.

For the present problem, there are several additional points to be considered. First, the recursive test is consistent only against increases in tail thickness (decrease in $\alpha$ ) beyond the breakpoint, a consequence of the fact that a part of the sample with thick tails dominates in estimation of $\alpha$. For this reason, although the recursive method is the standard approach to structural change tests in many contexts, the recursive tests will not allow us to examine potentially significant decreases in tail thickness following market reforms. We will therefore not rely on these tests, although we will mention their results below for the part of our problem to which they are applicable.

Second, the financial returns data that we examine here are not IID, but display second-moment dependence often modelled, for example, with GARCH processes. Quintos et al. provide modified versions of the test statistics using the results of Hsing (1991) for dependent processes, applying these to the squares of the logarithmic returns. The modifications are based on a re-scaling of each of the equations of (3.4) to account for the different variance of the Hill estimates when the raw data are serially dependent; with the appropriate re-scaling the same asymptotic distribution holds. These are the versions of the (rolling and sequential) tests that we employ below. If $\left\{X_{i}\right\}$ has tail index $\alpha$, then $\left\{X_{i}^{2}\right\}$ has tail index $\alpha / 2$; in the figures below we rescale the estimated tail index parameters by 2 to report the estimated tail index for the original series of logarithmic returns.

\section{EMPIRICAL RESULTS}

\subsection{Evolution of the tail index on the full samples}

The first set of empirical results concerns the hypothesis of constancy of the tail index on the full historical samples. The results, for rolling tests using various sample proportions and for the sequential tests, are presented in Table 1. 
Table 1

Full-sample rolling and sequential tests

DJIA and S\&P 500 index log returns

DJIA S\&P 500

\begin{tabular}{lccc}
\hline Test & $1 \%$ c.v. & $\sup \left(Z_{i}(t)\right)$ & $\sup \left(Z_{i}(t)\right)$ \\
Rolling, $\gamma=0.15$ & 1.90 & 13.9 & 3.12 \\
Rolling, $\gamma=0.20$ & 2.30 & 22.5 & 4.30 \\
Rolling, $\gamma=0.25$ & 2.55 & 27.6 & 5.29 \\
Rolling, $\gamma=0.30$ & 2.86 & 39.3 & 6.71 \\
Sequential, $t_{0}=500$ & 28.82 & 332.6 & 151.6 \\
\hline
\end{tabular}

These results are easily summarized. On all tests and on both equity price indices, the null of constancy of the tail index is rejected at a test level of 0.01 (the smallest tabulated); that is, each of the test statistics exceeds (by a substantial margin) the 99th percentile of the null distribution. ${ }^{4}$ The dates at which the maxima of the statistics occur are in general in the year preceding the $1987 \mathrm{crash}$; the pointwise statistics are in most cases above the $1 \%$ critical values for many dates in the neighbourhood of that time. For the Dow Jones Industrials data, the months in which the maximum statistics in the rolling tests occur vary from April 1986 $(\gamma=0.15)$ to October $1987(\gamma=0.20)$; in the sequential test, the maximum occurs in September 1998. In the S\&P data, the maxima occur between August 1982 $(\gamma=0.15)$ and October/December $1987(\gamma=0.25,0.30)$; note however from Figure 1e that the early peak is isolated and only slightly exceeds the statistics from 1987. The sequential test again shows a late maximum in October $1998 .^{5}$ All of these dates should be interpreted very cautiously, in part because the alternative hypothesis of a break at a particular date is not something that we wish to interpret literally

\footnotetext{
${ }^{4}$ As we noted above, we will not use the recursive test because of the lack of consistency against an increase in the tail index (decrease in tail thickness) over the sample. However, we note that the recursive statistics corresponding to those in Table 1 also show strong rejections of the null of constant $\alpha$ on the full samples, and that these tests are consistent against a substantial decrease in the tail index, as appears to have occurred in the neighbourhood of 1987.

${ }^{5}$ Recall that the sequential tests compare samples before and after a hypothesized break date, whereas rolling and recursive tests use data up to the particular date.
} 
for the present problem. Moreover we note from Quintos et al. (1991, esp. Table 3) that estimates of breakpoints may be quite poor, and even in favourable cases show substantial variability around the true date. Nonetheless, we do note that the strongest evidence of statistically significant change in the tail index does tend to occur in the period of interest.

The sequences of rolling statistics for a variety of sample proportions are presented in Figure 1 (a-d: DJIA; e-h: S\&P). Figure 2, which we will discuss in more detail below, clearly indicates that the change in the tail index around 1987 which is identified by the tests is in the direction of a fall in $\alpha$, that is, an increase in tail thickness and therefore in the relative frequency of extreme events.

\subsection{The tail index in the era of program trading and circuit breakers}

The next set of results concerns inference on the post-program-trading era for which, as described above, we use data from 2 January 1985. We are now interested in particular in the possibility that the tail index may have increased (tail thickness decreased) later in the sample, as circuit breakers were introduced. Since the first circuit breakers took effect in October of 1988, we have an initial sample of almost one thousand trading days on which to base pre-circuit-breaker estimates. Recall, however, that the severity with which these regulations bind has changed over time as the trigger points as a percentage of index value changed; there is therefore no fixed degree of severity of these circuit breakers, and no fixed date at which the process may be deemed to have changed from one fixed regime to another fixed regime. Nonetheless, we are able to test the null of constancy of the tail index.

We examine the possibility of a significant change in $\alpha$ in this later sample of data using the rolling and sequential tests which are consistent for a change in $\alpha$ in the direction described by this alternative hypothesis, i.e. to the extent that circuit breakers are successful in limiting extreme fluctuations, the implied change in $\alpha$ is positive (a decrease in tail thickness/frequency of extreme events). The results of the tests on the post-program-trading sub-sample, for which sample sizes are now identical in the DJIA and S\&P 500 index data, are presented in Table 2. 
Table 2

Sub-sample rolling and sequential tests

DJIA and S\&P 500 index log returns

DJIA $\quad$ S\&P 500

\begin{tabular}{lccc}
\hline Test & $1 \%$ c.v. & $\sup \left(Z_{i}(t)\right)$ & $\sup \left(Z_{i}(t)\right)$ \\
Rolling, $\gamma=0.15$ & 1.90 & 2.13 & 2.18 \\
Rolling, $\gamma=0.20$ & 2.30 & 2.48 & 3.56 \\
Rolling, $\gamma=0.25$ & 2.55 & 2.16 & 1.79 \\
Rolling, $\gamma=0.30$ & 2.86 & 4.61 & 1.90 \\
Sequential, $t_{0}=500$ & 28.82 & 32.4 & 35.1 \\
\hline
\end{tabular}

While evidence is weaker on this pair of smaller samples, there is still substantial evidence against the null of constancy of the tail index; both sequential statistics and five of the eight rolling statistics have p-values below 0.01 , and the remaining three rolling tests are in the upper $10 \%$ of the null distribution. As an aid to interpreting these results, consider again Figure 2a-d; note that we have recorded the recursive estimates only for the smaller rolling sample proportions $(\gamma=0.15,0.20)$, since as this proportion increases results from the latter part of the sample are blurred by the inclusion of more data from earlier periods. All four test statistics from these shorter spans reject the null of constancy at $1 \%$.

In each of the four individual figures, a clear jump in the estimated tail index is visible in the latter part of the sample (as $\gamma$ is larger, this jump is later, reflecting the fact that a given data point remains in the rolling sample for more periods). After this increase, the estimates of $\alpha$ tend to remain lower (frequency of extreme events higher) than the values attained in, for example, the 1960-1980 period. That is, these estimates suggest that the effect of the post-1987 reforms has been to raise the tail index, and the statistics in Table 2 are compatible with the significance of this effect. However, the estimates suggest that the effect of the reforms has not been so large as to return the tail index to levels prevailing before the era of program trading. We note however that the last conclusion is based on the point estimates alone, and is not supported by statistical inference on the relative magnitudes.

\section{Concluding Remarks}

A sequence of changes, both technological and regulatory, took place in US equity markets from the mid-1980's. A first goal of this paper is to consider whether corresponding changes can be observed in the pattern of extreme events in the equity 
markets, as summarized here by the tail index of the distribution of logarithmic returns, or whether by contrast the nature of the tail of the return distribution was approximately stable over this time period. The statistical evidence is very clear on this question, indicating very strong rejections of the hypothesis of constant tail behaviour. The datings of significant statistics in the sequence are compatible with the importance of the historical changes in market operation related to program trading. We conclude then that the markets began to display significantly more extreme behaviour at approximately this time.

The second question of interest is that of whether we can detect attentuating influences on extreme behaviour during the period of regulatory reform which followed the 1987 crash. On this point the evidence is less strong; nonetheless there is substantial evidence of further change in the pattern of extreme events, in the direction of a reduction in the frequency of extreme changes. However, the evidence tends to suggest that the frequency of extreme events remains higher than in, for example, the 1960-80 period. 


\section{REFERENCES}

Bertero, E. and C. Mayer (1990) Structure and Performance: Global Interdependence of Stock Markets Around the Crash of October 1987. European Economic Review 34, 1155-1180.

Booth, G.G. and J.P. Broussard (1998) Setting NYSE Circuit Breaker Triggers. Journal of Financial Services Research 13, 187-204.

Danielsson, J. (2001) Using a Bootstrap Method to Choose the Sample Fraction in Tail Index Estimation. Journal of Multivariate Analysis 76, 226-248.

DuMouchel, W.M. (1983) Estimating the Stable Index $\alpha$ in Order to Measure Tail Thickness: A Critique. Annals of Statistics 11, 1019-1031.

Feuerverger, A. and P. Hall (1999) Estimating a Tail Exponent by Modelling Departure from a Pareto Distribution. Annals of Statistics 27, 760-781.

Hill, B.M. (1975) A Simple General Approach to Inference about the Tail of a Distribution. Annals of Statistics 3, 1163-1174.

Hsing, T. (1991) On Tail Index Estimation Using Dependent Data. Annals of Statistics 19, 1547-1569.

Kearns, P. and A. Pagan (1997) Estimating the Density Tail Index for Financial Time Series. Review of Economics and Statistics 79, 171-175.

Lauterbach, B. and U. Ben-Zion (1993) Stock Market Crashes and the Performance of Circuit Breakers: Empirical Evidence. Journal of Finance 48, 1909-1925.

Lindsey, R.R. and A.P. Pecora (1998) Ten Years After: Regulatory Developments in the Securities Markets Since the 1987 Market Break. Journal of Financial Services Research 13, 283-314.

Loretan, M. and P.C.B. Phillips (1994) Testing the Covariance Stationarity of Heavy-Tailed Time Series. Journal of Empirical Finance 1, 211-248.

Ma, C.K., R.P. Rao and R.S. Sears (1989a) Limit Moves and Price Resolution: The Case of the Treasury Bond Futures Market. Journal of Futures Markets 9, 321-335.

Ma, C.K., R.P. Rao and R.S. Sears (1989b) Volatility, Price Resolution, and the Effectiveness of Price Limits. Journal of Financial Services Research 3, 165-199.

Quintos, C., Z. Fan and P.C.B. Phillips (2001) Structural Change Tests in Tail Behaviour and the Asian Crisis. Review of Economic Studies 68, 633-663.

Roll, R. (1989) Price Volatility, International Market Links, and their Implications for Regulatory Policies. Journal of Financial Services Research 3, 211-246. 
Santoni, G.J. and T. Liu (1993) Circuit Breakers and Stock Market Volatility. Journal of Futures Markets 13, 261-277. 
Figure 1a:

Rolling test statistic; Window:

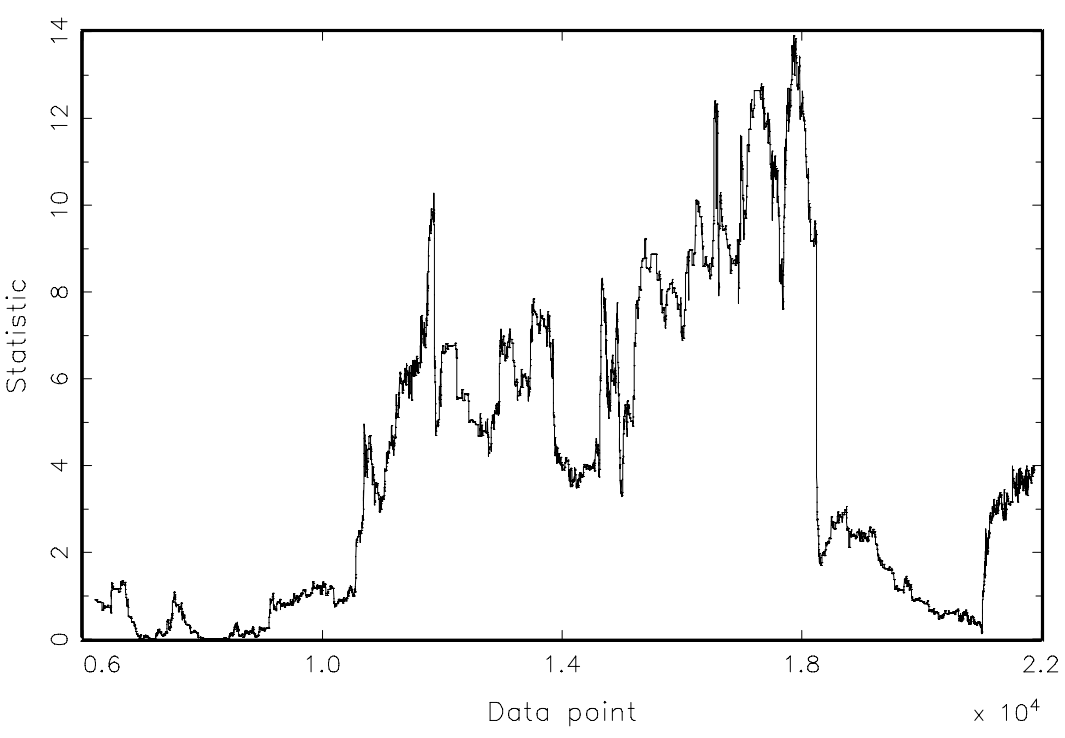

Figure 1c:

Rolling test statistic; Window: 0.25 Data: InDJIA

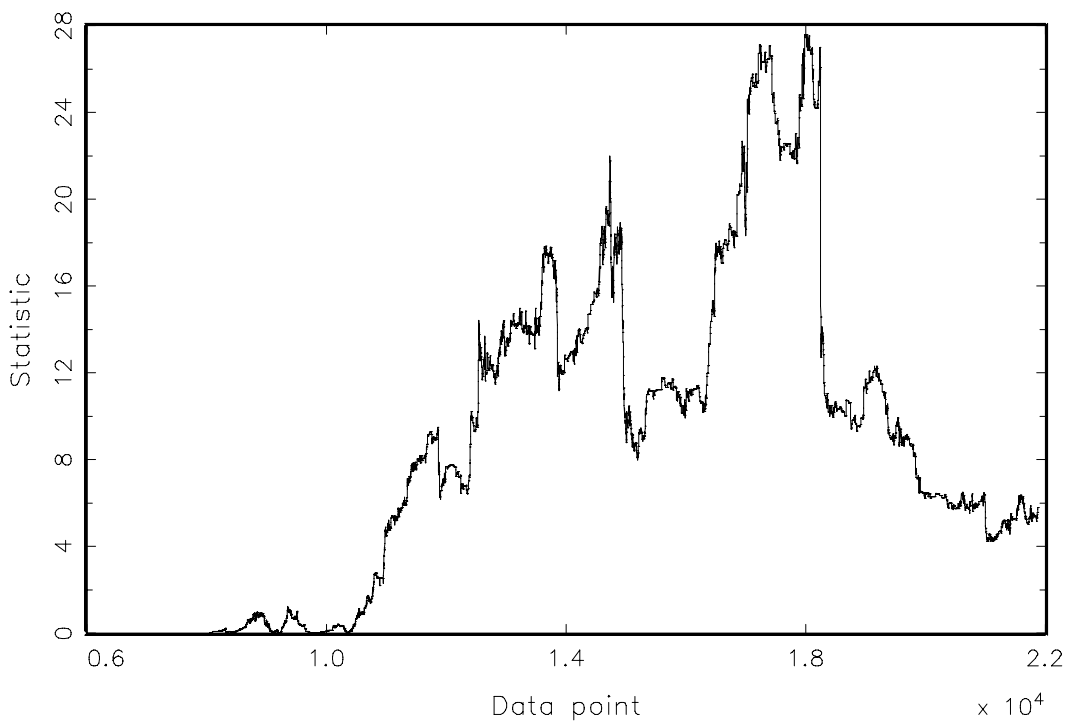

Figure $1 \mathrm{~b}$ :

Rolling test statistic; Window:

0.20 Data: InDJIA

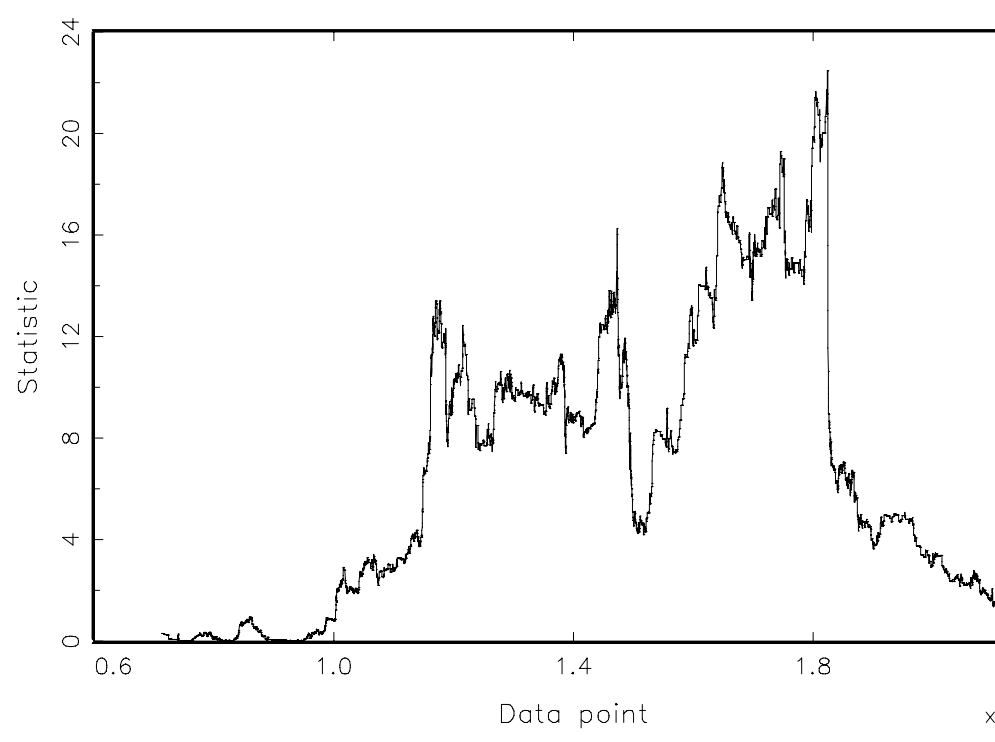

Figure 1d:

Rolling test statistic; Window:

0.30 Data: InDJIA

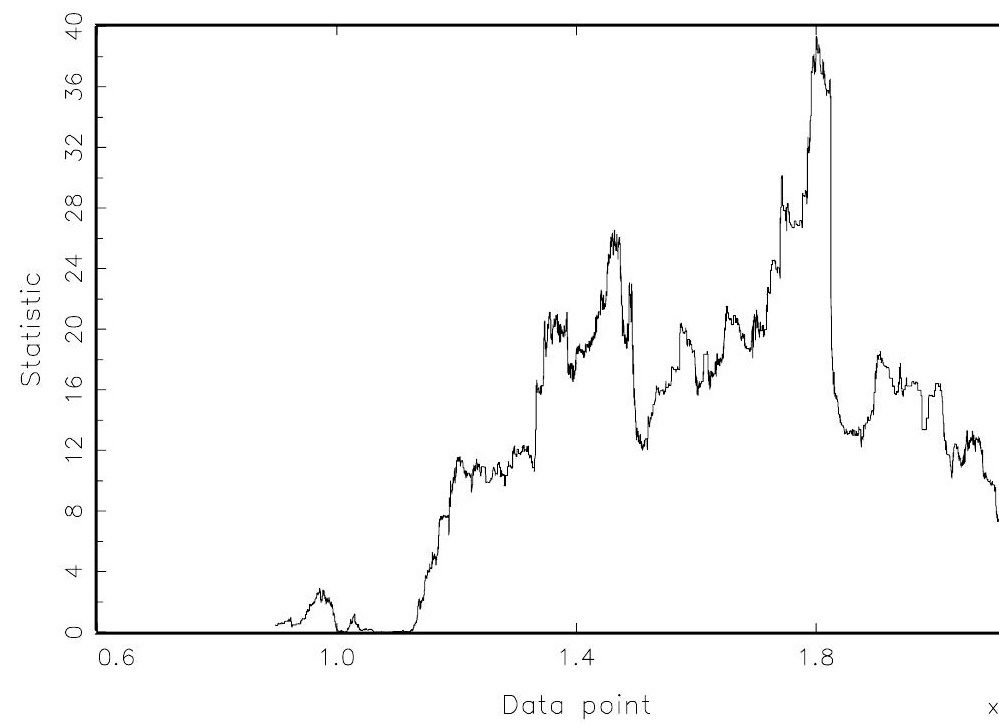


Figure 2a:

Rolling tail index estimate, window $=0.10$, DJIA log returns

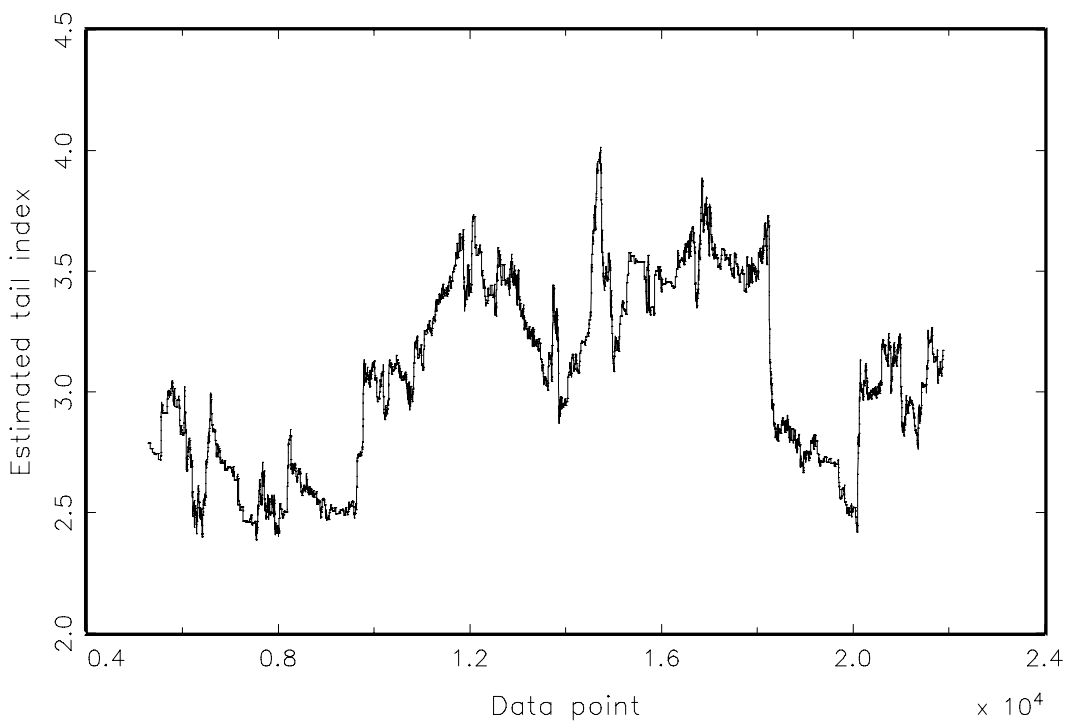

Figure 2c:

Rolling tail index estimate, window $=0.15$, DJIA log returns

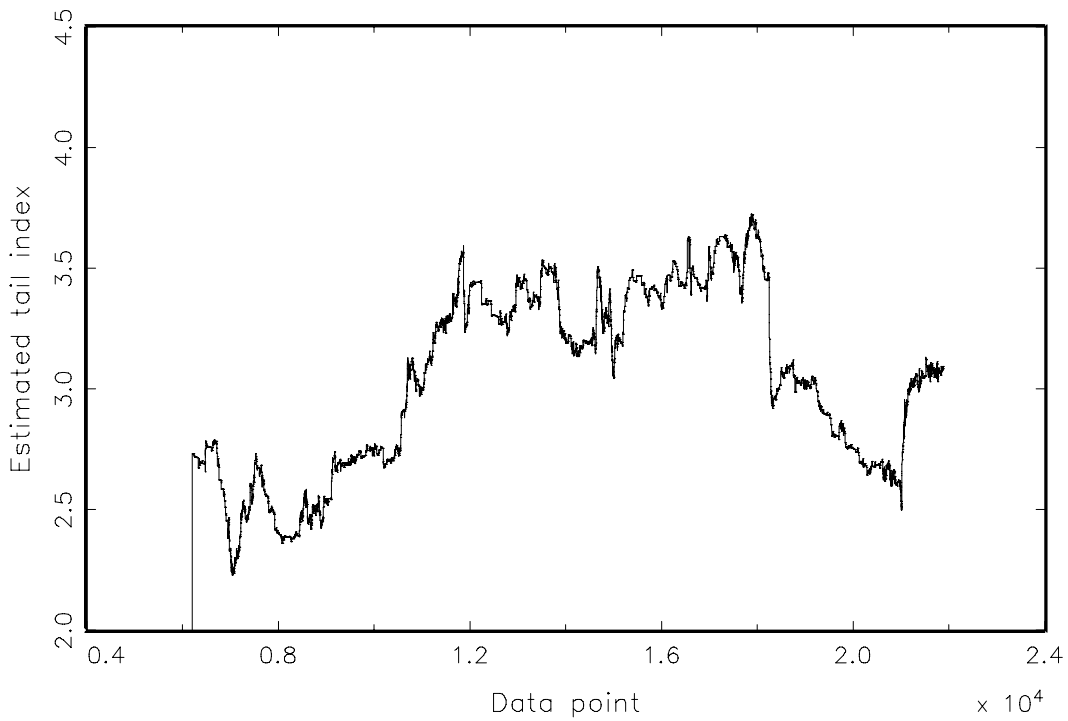

Figure 2b:

Rolling tail index estimate, window $=0.10$, SP500 log retu

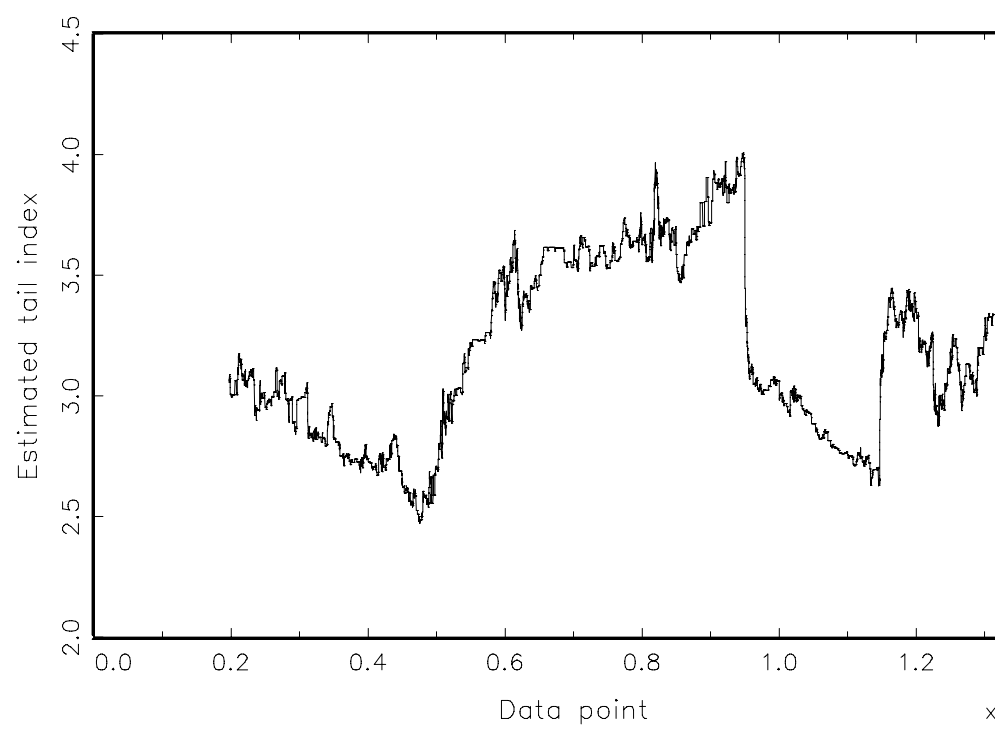

Figure 2d:

Rolling tail index estimate, window $=0.15$, SP500 log retu

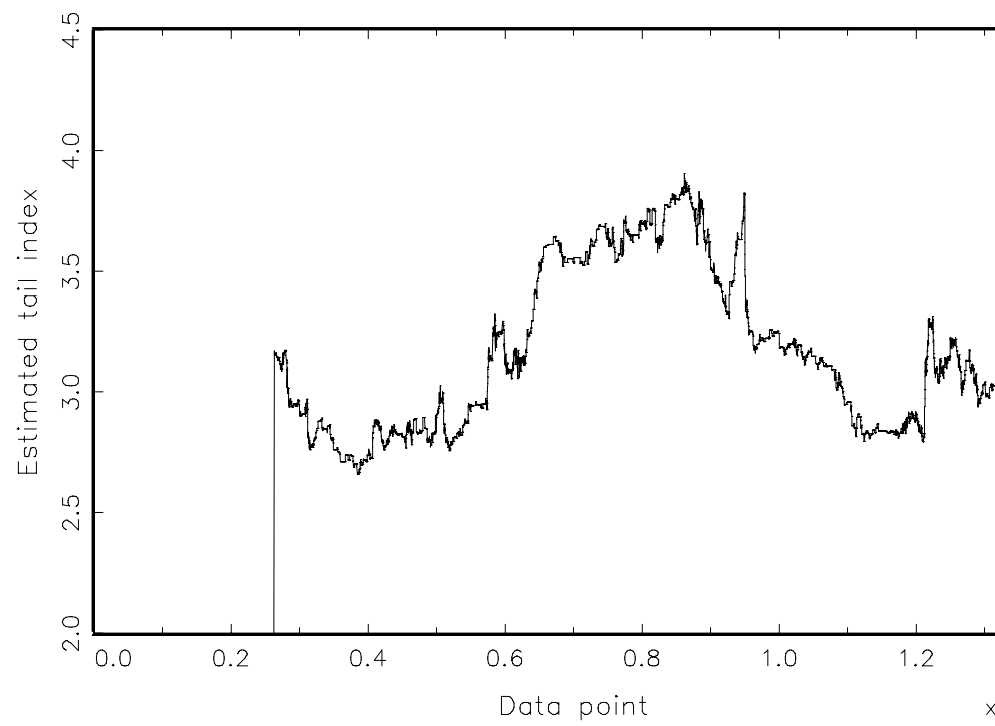

